\title{
Specificity of Acceleration, Maximum Speed, and Agility in Professional Soccer Players
}

\author{
Thomas Little ${ }^{1}$ and Alun G. Williams ${ }^{2}$ \\ ${ }^{1}$ Sport, Health and Exercise, Staffordshire University, Stoke-on-Trent, Staffordshire, United Kingdom; ${ }^{2}$ Institute \\ for Biophysical and Clinical Research Into Human Movement, Manchester Metropolitan University, Alsager, \\ United Kingdom.
}

\begin{abstract}
Little, T., and A.G. Williams. Specificity of acceleration, maximum speed, and agility in professional soccer players. J. Strength Cond. Res. 19(1):76-78. 2005.-High-speed actions are known to impact soccer performance and can be categorized into actions requiring maximal speed, acceleration, or agility. Contradictory findings have been reported as to the extent of the relationship between the different speed components. This study comprised 106 professional soccer players who were assessed for 10-m sprint (acceleration), flying 20-m sprint (maximum speed), and zigzag agility performance. Although performances in the three tests were all significantly correlated $(p<$ 0.0005), coefficients of determination $\left(r^{2}\right)$ between the tests were just 39,12 , and $21 \%$ for acceleration and maximum speed, acceleration and agility, and maximum speed and agility, respectively. Based on the low coefficients of determination, it was concluded that acceleration, maximum speed, and agility are specific qualities and relatively unrelated to one another. The findings suggest that specific testing and training procedures for each speed component should be utilized when working with elite players.
\end{abstract}

KEY WoRDS. fitness testing, speed, soccer

\section{INTRODUCTION}

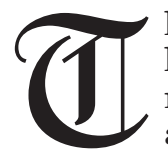

he capacity of soccer players to produce varied high-speed actions is known to impact soccer match performance (10). Although high-speed actions only contribute to $\sim 11 \%$ of the total distance covered, they in fact constitute the more crucial moments of the game and contribute directly to winning possession of the ball and to scoring or to conceding of goals (13). Superior performance in varied speed tests of professional players, compared with both the general population and the higher standards of soccer, indicates that certain speed attributes are advantageous for elite soccer (8).

High-speed actions during soccer competition can be categorized into actions requiring acceleration, maximal speed, or agility. Acceleration is the rate of change in velocity that allows a player to reach maximum velocity in a minimum amount of time. Maximum speed is the maximal velocity at which a player can sprint. Agility does not have a global definition, but it is often recognized as the ability to change direction and start and stop quickly (6). The range of sprint distances recorded during games $(1.5-105 \mathrm{~m})$ indicates the requirements of both acceleration and maximum speed capacities (2). Although the average sprint distance is small $(17 \mathrm{~m} ; 2)$, players often initiate sprints when already moving at moderate speeds (19). Therefore, top speed will be achieved more often than distance or time parameters would otherwise predict. Many instances in soccer demand rapid changes of direction. Withers et al. (17) have shown that players make an average of 50 turns per game.

Similar morphological and biochemical determinants of acceleration, maximal speed, and agility (i.e., fiber type proportion) had led to the assumption that these qualities are highly related. Research concerning the interrelationship of the speed qualities has, however, been inconsistent in its findings, and certain areas still require investigation. Delecluse (4) found maximal speed and acceleration to be specific qualities in sprint athletes. However, field sport athletes are believed to have different running mechanics than sprint athletes (14), and significant correlations between acceleration and maximum speed in professional rugby league players have been reported (1). Pauole et al. (12) found significant correlations between performance in an agility T-test and 40-yard sprint time in both men and women. In contrast, Buttifant and Graham (3) and Young et al. (18) reported no significant correlations between straight sprinting and agility speed tests in either Australian soccer or Australian Rules football players. Furthermore, both Draper and Lancaster (5) and Mayhew et al. (11) reported low common variances of $21 \%$ between tests for straight sprinting speed and agility. Interestingly, Young et al. (20) examined the specificity of the training response to straight sprint or agility training over a 6 -week period and found that a training method specific to one speed quality produced limited transfer to the other. Also, Little and Williams (9) presented preliminary data regarding professional soccer players which suggested that acceleration, maximum speed, and agility are relatively independent qualities. However, the findings may have been a derivative of the study's relatively small sample size and range of results. The small range of data when dealing with a relatively homogenous population dictates that a large number of subjects must be sampled in order to obtain sufficient statistical power (7). Therefore, for a more accurate reflection of the extent of the relationship between acceleration, maximum speed, and agility in professional soccer players, similar research with a large number of subjects is required.

Thus, the purpose of this study was to determine the extent to which top speed, acceleration, and agility are distinct physical attributes in professional soccer players. It is our hypothesis that these speed qualities will be shown to be relatively independent qualities in such a population. Such knowledge would help sports scientists and soccer coaches choose appropriate testing and training procedures when working with elite soccer players. 


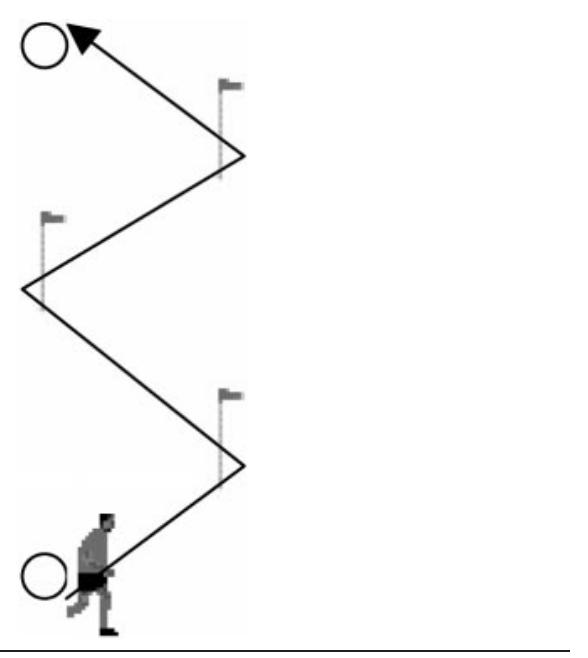

Figure 1. Diagram of the course used in the agility test. Each straight sprint is $5 \mathrm{~m}$ and each turn at a flag is $100^{\circ}$.

\section{Methods}

\section{Experimental Approach to the Problem}

One hundred and six male professional soccer players from English League teams (Nationwide Divisions 1 \& 2), aged 18-36, were tested as part of their athletic training program during the first quarter of the 2002-2003 competitive season. All subjects gave their informed consent and the study was approved by the Sport, Health, and Exercise ethics committee at Staffordshire University, Stoke-on-Trent, Staffordshire, UK. Tests of acceleration, maximum speeds, and agility were conducted on a single day for each test subject.

\section{Testing}

Acceleration was evaluated using a $10-\mathrm{m}$ test, involving sprinting $10 \mathrm{~m}$ as fast as possible from a stationary start position, as previously used by Wilson et al. (16). Maximum speed was assessed using a flying $20-\mathrm{m}$ test, involving a maximum $20-\mathrm{m}$ sprint from a maximum speed start that was ascertained during a $30-\mathrm{m}$ run-up before the start. Agility was tested using a zigzag course consisting of four $5-\mathrm{m}$ sections set out at $100^{\circ}$ angles (Figure 1 ). This zigzag test was chosen because it required the acceleration, deceleration, and balance control facets of agility, and the familiarity of the subjects with the test and its relative simplicity also meant that learning effects would be minimal. All tests were performed on an indoor synthetic pitch, and electronic timing gates were used to record completion times (Brower Timing System, Salt Lake City, UT). Tests were conducted in this order: stationary 10-m, flying 20-m, and agility test. Subjects performed two trials of each test, with at least 2 minutes of rest between all trials and tests. The best performances in each test were used for analysis. All tests were conducted $>48$ hours following a competition or hard physical training to minimize the influence of fatigue on test performance.

\section{Statistical Analyses}

The relationships between the performances on the acceleration, maximum speed, and agility tests were determined by Pearson correlations $(r)$, whereas coefficients of
TABLE 1. Mean $( \pm S D)$ time taken for the 3 speed tests.

\begin{tabular}{ll}
\hline $10-\mathrm{m}$ test (acceleration) & $1.83 \pm 0.08 \mathrm{~s}$ \\
Flying $20-\mathrm{m}$ test (maximum speed) & $2.40 \pm 0.11 \mathrm{~s}$ \\
Zigzag test (agility) & $5.34 \pm 0.20 \mathrm{~s}$ \\
\hline
\end{tabular}

TABLE 2. The relationships between the performances on the 3 speed tests.

\begin{tabular}{lccc}
\hline Relationship assessed & $r$ & $r^{2}$ & $p$ value \\
\hline $\begin{array}{l}\text { Acceleration and } \\
\quad \text { maximum speed }\end{array}$ & 0.623 & 0.388 & $p<0.0005$ \\
$\begin{array}{l}\text { Acceleration and } \\
\quad \text { agility }\end{array}$ & 0.346 & 0.119 & $p<0.0005$ \\
$\begin{array}{l}\text { Maximum speed and } \\
\text { agility }\end{array}$ & 0.458 & 0.209 & $p<0.0005$ \\
\hline
\end{tabular}

determination $\left(r^{2}\right)$ were used for interpreting the meaningfulness of the relationships.

\section{RESULTS}

Mean times $( \pm S D$ ) for all tests are shown in Table 1 . The correlations and coefficients of determination between the various tests are shown in Table 2.

\section{Discussion}

The performances on the $10-\mathrm{m}$ test for acceleration, the flying 20-m test for maximum speed, and the zigzag test for agility were all correlated at high levels of statistical significance $(p<0.0005)$. These data would initially suggest that acceleration, maximum speed, and agility share common physiological and biomechanical determinants. However, the coefficients of determination show that even the most significantly correlated tests, acceleration and maximum speed, share only $39 \%$ common variance. Thomas and Nelson (15) state "when common variance between the two variables is less than $50 \%$, it indicates that they are specific or somewhat independent in nature." As such, it appears that acceleration, maximum speed, and agility are relatively independent attributes in professional soccer players. The requirement of high power production during each of the three tests, which itself partly depends upon the ratio of leg strength to body mass and fiber type proportion, means that the different speed components do indeed share some relation. However, our results suggest that some different factors contribute to successful performance in each speed discipline.

These findings confirm a recent preliminary report that found acceleration, maximum speed, and agility to be relatively independent attributes in professional soccer players (9), although slightly different tests were used for maximum speed and agility. The small range of data observed within the sample of 35 subjects in the earlier research reduced the possibility of observing high correlations between the tests (7). The greater sample size of 106 for the present study minimizes the chance that a low range of data will mask high correlations; therefore, the conclusion that acceleration, maximum speed, and agility are specific qualities in professional soccer players appears justified.

The present results confirm earlier findings that acceleration and maximum speed (4), and straight sprinting 
speed and agility $(3,5,11,18$, ) are specific qualities. Disparity with previous research $(1,12)$ may be partly attributable to the various methods of measuring the differing speed qualities. As yet, no criterion tests exist for acceleration, maximum speed, or agility. Further work is needed to address this issue if research concerning sprint performance is to progress in a coherent manner.

The results from the cross-sectional study design used in the present study concur with those from a longitudinal study. Young et al. (20) examined the specificity of the training response to straight sprint or agility training over 6 weeks. Straight sprint training (20-40 m) significantly improved $30-\mathrm{m}$ sprint performance, but performance improvements decreased as the agility requirements (number and severity of directional changes) increased. Similarly, the agility training resulted in significant improvements in the change-of-direction tests, but no significant improvement in straight sprint performance. These results suggest that straight speed and agility training methods produce specific gains in performance that have limited transfer to the other performance mode. Thus, the present results and those from the longitudinal study suggest that differing physiological and biomechanical factors contribute to successful performance in each speed discipline.

The present findings suggest that specific testing procedures for acceleration, maximum speed, and agility should be utilized in sports science support work with elite soccer players. Further work is required to decipher which physiological and biomechanical factors determine performance in each of the 3 speed tests, and thereby identify the cause of the specificity of the different speed components. The specificity of acceleration, maximum speed, and agility that we observed may be attributable to differences in the musculature recruited; in the requirements for strength to be developed at specific muscle lengths; in the requirements for strength to be developed in either shortening or lengthening contraction modes; or in the complex motor control and coordination of several muscle groups (refer to Young et al. [19, 21] for further discussion). Knowledge of the physiological and biomechanical factors that determine performance in each of the 3 speed tests will allow specific training programs to be designed to address player weaknesses, to improve speed capability of players in relation to their position on the field of play, and ultimately, to improve match performance.

\section{Practical Applications}

Athletic trainers, fitness coaches, and sports scientists who work to improve speed in elite athletes should be aware that acceleration, maximum speed, and agility are distinct qualities. When testing these components of speed, specific tests should be used that evaluate the speed components of importance to the sport in question. For elite soccer players, a $10-\mathrm{m}$ test of acceleration, a flying $20-\mathrm{m}$ test of maximum speed, and a zigzag test of agility would be suitable. Ultimately, it is also likely that effective training procedures to improve acceleration, maximum speed, and agility will include specific training drills.

\section{REFERENCES}

1. BAKER, D., AND S. NANCE. The relation between running speed and measures of strength and power in professional rugby league players. J. Strength Cond. Res. 13:230-235. 1999.

2. BANGSBO, J. The physiology of soccer: With special reference to intense physical exercise. Acta. Physiol. Scand. 150:1-156. 1994.

3. Buttifant, D., K. Graham. And K. Cross. Agility and speed of soccer players are two different performance parameters. $J$. Sports Sci. 17:809. 1999.

4. Delecluse, D. Influence of strength training on sprint running performance: Current findings and implications for training. Sports Med. 24:147-156. 1997.

5. DRAPER, J.A., AND M.G. LANCASTER. The 505 Test: A test for agility in the horizontal plane. Aust. J. Sci. Med. Sport. 17:1518. 1985.

6. Gambetta, V. How to develop sport-specific speed. Sports Coach. 19:22-24. 1996.

7. Hopkins, W.J., L. HARLEY, AND L. BuRKe. Design and analysis of research on sport performance enhancement. Med. Sci. Sports Exerc. 31:472-485. 1999.

8. Kollath, E., AND E. QuAdE. Experimental measures of professional and amateur soccer players' sprinting speed. In: Science and Football II. T. Reilly, J. Clarys, and A. Stibbe, eds. London: E. \& F.N. Spon, 1993. pp. 31-36.

9. Little, T., AND A.G. Williams. Specificity of acceleration, maximum speed and agility in professional soccer players. In: Fifth World Congress of Science and Football. Madrid: Gymnos, 2003. pp. 144-145.

10. LuHTANEN, P. Biomechanical aspects. In: Football (Soccer). B. Ekblom, ed. Oxford: Blackwell Scientific Publications, 1994. pp. 59-77.

11. Mayhew, J., F. Piper, T.M. Schwegler, and T.E. Ball. Contributions of speed, agility and body composition to anaerobic power measurements in college football players. J. Appl. Sports Sci. Res. 3:101-106. 1989.

12. Pauole, K., K. Madole, And M. Lacourse. Reliability and validity of the T-test as a measure of agility, leg power and leg speed in college aged men and women. J. Strength Cond. Res. 14:443-450. 2000

13. Reilly, T., J. BANGsbo, AND A. Franks. Anthropometric and physiological predispositions for elite soccer. J. Sports Sci. 18: 669-683. 2000.

14. SAYERS, M. Running techniques for field sport players. Sports Coach. 23:26-27. 2000.

15. Thomas, J.R., AND J.K. NeLson. Research Methods in Physical Activity (4th ed.). Champaign, IL: Human Kinetics, 2001.

16. Wilson, G.J., R.U. Newton, A.J. MurPhy, AND B.J. HumPHRIES. The optimal training load for the development of dynamic athletic performance. Med. Sci. Sports Exerc. 25:12791286. 1993

17. Withers, R.T., Z. Maricic, S. Wasilewski, and L. Kelly. Match analysis of Australian professional soccer players. $J$. Hum. Mov. Stud. 8:159-176. 1982.

18. Young, W., M. Hawken, AND L. McDonald. Relationship between speed, agility and strength qualities in Australian Rules football. Strength Cond. Coach. 4:3-6. 1996.

19. Young, W., D. Benton, G. Duthie, And J. Pryor. Resistance training for short and maximal speed sprints. Strength Cond. 23:7-13. 2001.

20. Young, W.B., M.H. McDowell, AND B.J. Scarlett. Specificity of sprint and agility training methods. J. Strength Cond. Res. 15:315-319. 2001.

21. YounG, W.B., R. JAmes, AND I. Montogomery. Is muscle power related to running speed with changes of direction? J. Sports Med. Phys. Fit. 42:282-288. 2002.

Address correspondence to Thomas Little, dosmas2000@ aol.com. 